\title{
Assessment of Digital Skills in Serbia with Focus on Gender Gap
}

\author{
Aleksandra Bradić-Martinović ${ }^{1}$ \\ Jelena Banović ${ }^{2}$ \\ Institute of Economic Sciences, Belgrade, Serbia
}

\section{A B S T R A C T}

The world is constantly changing creating a new environment. One of the main factors in this process is the Digital Transformation which requires adjustment of skills, institutions, processes and business models. The European Commission started to cope with this topic in last twenty years and today their activities are according to the "Europe 2020 Strategy." Enhancement of digital skills is one of the priority. Serbia also makes an effort in this area and policymakers already adopted several documents and policies. The main issue is a lack of scientific research that cover the subject - ex ante and ex-post analysis of adopted policies. We consider this subject very important having in mind that the digital skills become one of the basic element for the national growth and competitiveness.

This paper presents findings on the existing level of digital skills of the workforce in Serbia, with focus on the gender gap. Findings are based on a standardized survey conducted during September 2017, within the pilot study research. Results show that the level of digital skills is Serbia is lagging behind the EU average and that the level of digital skills of Serbian women is lower than men.

KEY WORDS: digital literacy, digital skills, digital divide, gender gap, Serbia, indicator, EU, public policy

\footnotetext{
${ }^{1}$ Zmaj Jovina 12, 11000 Belgrade, Serbia, e-mail: abmartinovic@ien.bg.ac.rs

${ }^{2}$ Zmaj Jovina 12, 11000 Belgrade, Serbia, e-mail: jelena.banovic@ien.bg.ac.rs
} 


\section{Introduction}

Within the traditional economy, developed and developing countries differed in their ability to access and dispose of raw materials, physical capital (machines, factories, roads) and human capital (educated workforce) which are necessary for economic development. The world of the twentyfirst century is constantly changing, dominantly through technology innovations. However, within the new economy, there is a polarization between the developed and the developing countries on access to ideas, knowledge and modern ICT. Kolaković, Mariković \& Stefanović (2009) pointed out that "depending on the level of development, countries are facing challenges of the effective and efficient use of digital resources, with more or less success". Developing countries promote digital transformation, but the leaders in this process are aware that one of the main preconditions for the accomplishment of this goal is the ability of the population to use technology successfully, i.e. to have necessary Digital Literacy and Skills. Radović-Marković et al. (2017) even narrow this issue and confirm that "dynamic business environment requires a permanent increase in the educational level of entrepreneurs".

The Digital Skills, in the context of this paper, can be observed through dual lenses. First is the general level of Digital Skills within the workforce and the second is issues of the digital gender gap, as a reason for digital divide and skills mismatch in the labour market, which gained significance in the last ten years. For example, data show (Zhao, 2016) that there are 200 million online men in the world more than women. Zhao states that "closing the digital gender divide is a pressing concern". Radović-Marković (2011) conclude that women need to focus more on learning "21st-century skills, such as problem solving, critical thinking, and collaboration".

The European Commission (EC) responded on these topics and adopted a new "Digital Education Action Plan" in January 2018. Among eight key competencies, this document includes digital and entrepreneurship skills. It states (European Commission, 2018) that $90 \%$ of future jobs will require digital skills, $44 \%$ of Europeans are lack of these skills, less than $20 \%$ of ICT professionals are women and that more than 48,000 schools are lack of internet connection. The plan foresees the following priorities: improvement within digital technology in the area of education; adjustment of digital skills and competencies for the digital transformation and improvement of education based on data analysis and foreseen. The EC founds that digital literacy is also necessary for life-long learning. 
Beside the Action Plan, EC (2015) also implements "Digital Single Market Strategy" and "Skills Agenda for Europe" (2016) which promotes the enhancement of digital skills. One of the latest document published by EC (2018) is a report study on "Women in the Digital Age" which "identifies key factors and trends in the participation of women in ICT and its dynamics and analyses the practices enabling women's participation in the digital world".

Serbia is also aware of the significance of the digitalization and its impact on the society and economy. The first steps in this area were made a few years ago when GOPA Consultants and the European Association for the Education of Adults (EAEA) supported the project "Second Chance". One of the main objectives of the project was "establishing a system of functional elementary adult education in Serbia, which is accessible and adaptable to the needs of adult learners, focused on life skills and competencies and based upon lifelong learning" (Adult Education Society, 2010). As a follow-up activity, Aleksić et al. (2013) published "General Standards for the Basic Education of Adults - Digital Literacy".

In accordance with the The Strategy for Education Development in Serbia until 2020 (Official Gazette RS, no. 107/2012) which recognizes the importance and the role of new technologies for improving the education system and the Guidelines for Improving the Role Information and Communication Technologies in Education that the National Education Council adopted in December 2013, the Ministry of Education, Science and Technological Development of the Republic Serbia announces the Digital Competences Framework - Teacher for a Digital Age (2017). This document provides new insights to current initiatives in several areas: incessant investments in ICT infrastructure, reform of educational programs and adjusting curricula to a new circumstance, development of selfevaluation framework, mitigation of digital divide, and so forth.

This paper aims to show the position of Serbia among other European countries based on the results of Digital Skills indicator published by EUROSTAT and to open a particularly important topic - Digital gender gap, based on the pilot study research of women in Serbia.

\section{Literature Review}

Digital literacy and digital skills are not synonyms. Gui \& Argentin (2011) proposes that digital skills can be understood as the technical 
knowledge that enables the use of computers and other related devices. Individuals with digital skills can create files, receive and send emails as a result of following routine steps. Digital literacy is a broader concept and implies digital skills, but also the ability to understand, evaluate and reuse information. Digital Literacy, similar to general literacy, provides "the personal capability for the achievement of valued outputs in life, especially in the modern digital economy" (Chetty et al., 2017) and to "participate in the emerging knowledge society of the twenty-first century" (Khateeb, 2017). It is also important to highlight that digital competence person understand different information, know how to recognize good and inadequate sources of information, and to connect different sources.

According to Covelo (2010), this field is not standardized. On a global level, it is a lack of unique definitions or measures for the current state of development of this phenomena. Besides that, the problem is undefined domain of research - pedagogical or functional and validity of selfreporting.

Martin \& Grudziecki (2006) propose three levels of Digital Literacy. The lowest level is Digital competence, the second is Digital Usage, and the third is Digital Transformation. Each level covers specific personal engagement, from technical skills to innovation and creativity, as presented in Figure 1.

Figure 1: Levels of Digital Literacy

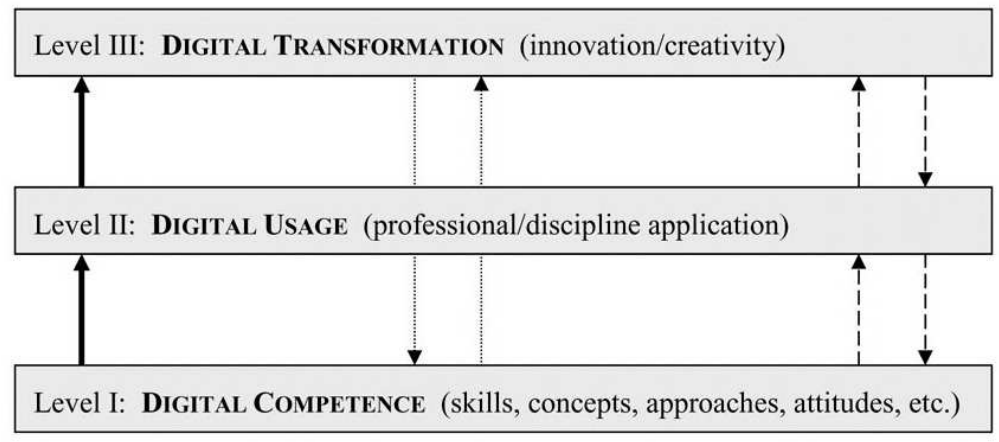

Source: Martin \& Grudzeicki (2006)

Ainley, Schulz \& Fraillon (2016) present four cross-country assessments of digital and ICT literacy skills: 
- IEA International Computer and Literacy Study (ICILS);

- Program for International Student Assessment (PISA) Digital Reading Assessment;

- Assessment and Teaching of 21st Century Skills (AT21CS), and

- Program for the International Assessment of Adult Competencies (PIAAC).

They conclude that the differences between these approaches are not significant and that would not be challenging to propose global indicator or index for assessment of digital literacy.

Scientists in Serbia have begun to deal more with the phenomena of digital literacy in the last decade, but the research is rare and nonsystematic. One of the most valuable empirical studies of Serbian society is „Digital literacy of employers and students in Serbia“, provided by Lakić et al. (2012) which covered 733 employers and 344 students. This research is a step further because it is based on Eurostat methodology and its results are comparable with other EU countries.

Digital literacy can be observed as a homogeneous phenomenon, but it can also be analyzed in relation to gender, race, employment status, etc. In this paper, we put emphasis on the gender dimension of digital skills. Hilbert (2011) shows that from early 1990s women is lagging behind men and the technology was male dominant. The situation started to change in new millennium and women started to use technology in developed and developing countries. The gender gap becomes narrower, but it still remains. Hafkin \& Huyer (2007) share the same conclusions, but highlight the lack of data for women in ICT, especially for developing countries and that the official statistics lack gender dimension.

Few studies (Jones, Johnson-Yale, Millermaier \& Seoane Perez, 2009; Gunkel, 2003) shows that male respondents in the survey spend more time online than female respondents. Bimber's (2000) findings confirm stated conclusions.

Today, this issue is still in focus of policymakers. In March 2018 European Parliament - Policy Department for Citizen's Rights and Constitutional Affair published a study "The Underlying Causes of the Digital Gender Gap and Possible Solutions for Enhanced Digital Inclusion of Women and Girls" (2018). This study aimed to find the factors which influence women to have an unequal position regarding access to digital technology. 


\section{Methodology and Data}

In this paper, we applied the methodology proposed by Eurostat for the statistics on the Information Society. In the year 2002 European Commission started to implement annual Information Society Survey - ICT Usage in households and by individuals. The questionnaire covers the following areas:

- Access to selected IC technologies (data collected at the household level);

- Use of computers, location, the frequency of use, activities (data collected at the individual level);

- Use of the Internet (data collected at the individual level);

- Internet commerce (data collected at the individual level);

- E-skills; the mobile use of the Internet - ubiquitous connectivity; cloud computing, e-government; trust and security.

Through the years EC changed and improved the content of the Survey to meet new conditions and regulation in this, very dynamic area. All EU countries, with a few candidate countries (Serbia, Montenegro, Macedonia and Turkey) are covered with the Survey. For EU countries data series cover the period 2003-2017, while Serbia joined the research in 2006.

Based on the Survey results, Eurostat publishes the data for Individuals' level of computer skills (isoc_sk_cskl_i) for the period 20032014, Individuals' level of internet skills ( $i s o c_{-} s k_{-} i s k l_{-} i$ ) for the period 2005-2013 and Individuals' level of digital skills (isoc_sk_dskl_i) for the period 2015-2017.

To enable easier monitoring this phenomenon and comparison of data between countries, DG CONNECT and the Eurostat Information Society Working Group created a new comprehensive Digital Skills (DS) indicator. The DS indicator consists of four dimensions, Information skills, Communication skills, Problem solving skills and Software skills for content manipulation.

Information skills include the ability to copy or move files and folders, to save files on Internet cloud spot, to obtain information from websites published by public authority, to find market information for goods or services and to seek information about health and wellbeing. The definition in DigiComp 2.1 states that the person with information skills can 
"identify, locate, retrieve, store, organize and analyze digital information, judging its relevance and purpose" (Carretero, Vuorikari \& Punie, 2017).

Communication skills include the ability to send and receive e-mails, to participate in e-social networks, to make telephone or video calls over the internet and to upload self-created content and to share it on the website. The definition in Digicomp 2.1 states that the person with communication skills can "communicate in digital environments, share resources through online tools, link with others and collaborate through digital tools, interact with and participate in communities and networks, cross-cultural awareness" (Ibid).

Problem-solving skills are consisting of two parts, problem-solving and familiarity with online services. Problem-solving skills include the ability to transfer files between computers or other devices, to install software applications and to changing software settings, including operating systems (OS) and security programs. Familiarity with online services includes the ability to purchase online, to sell online, and to use online learning resources and e-banking. The definition in Digicomp 2.1 states that the person with problem-solving skills can: "identify digital needs and resources, make informed decisions as to which are the most appropriate digital tools according to the purpose" (Ibid).

Software skills for content manipulation also consist of two parts, basic and above basic skills. Basic skills include the ability to use software for word processing, spreadsheet, edit photos, video or audio files, while Above basic skills include the ability to create presentation or document integrating text, pictures, tables or charts, to use advanced functions of spreadsheet to organize and analyze data (sorting, filtering, using formulas, creating charts) and to write a code in a programming language. The definition in Digicomp 2.1 states that the person with problem-solving skills can: "identify digital needs and resources, make informed decisions as to which are the most appropriate digital tools according to the purpose" (Ibid).

Dimensions of DS indicator, presented above, are covered by several questions in the questionnaire "ICT Usage in households and by individuals" and valued by scheme presented in "Methodological introduction" (http://ec.europa.eu/newsroom/dae/document.cfm?doc_id =14342). Finally, the results of individual indicators combine into Digital Skills indicator. 
Following the EU example, for this pilot research, we construct similar questionnaire which covers all areas necessary for calculating each part of the main indicator with DS indicator, as a final result.

\section{Results}

The data has been collected by standardizing face-to-face interview in September 2017 on a sample of 200 respondents age 16-64. We obtain 164 completed questionnaires. The sample consists of 53\% of female and $47 \%$ of male respondents. For an age range, we use OECD range proposal, and our sample has the following structure, $6 \%$ are in range $15-24,71 \%$ are in range 25-54 and the rest $23 \%$ are in range 55-64. Among respondents, $31 \%$ is unemployed, while $69 \%$ are in some form of employment. The level of education is presented in Figure 1.

Figure 1: The education structure of the respondents

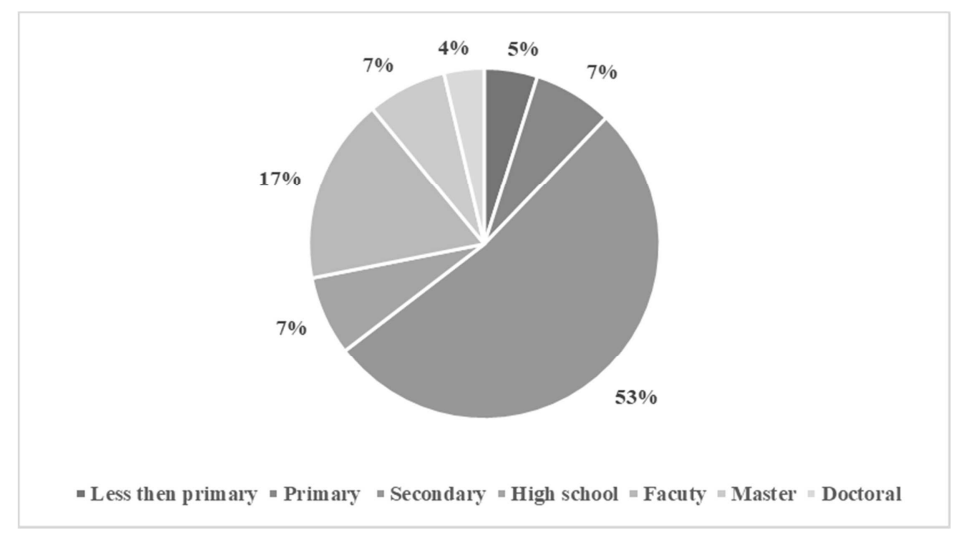

Source: Own survey

The $57 \%$ of respondents use the computers in their working places, while the rest do not.

Based on the answers and according to the EU methodology we calculate frequencies for each dimension of DS indicator. The results for the first dimension - Information skills are presented in Table 1. 
Table 1: Information skills frequency

\begin{tabular}{lcccc}
\hline \multirow{2}{*}{ Level } & \multicolumn{2}{c}{ All respondents } & \multirow{2}{*}{ Women } & \multirow{2}{*}{ Men } \\
& Survey & Eurostat & & \\
\hline No skills & 32.2 & 32.0 & 40.0 & 23.1 \\
Basic skills & 7.3 & 9.0 & 5.6 & 15.4 \\
Above basic skills & 60.5 & 59.0 & 54.4 & 71.5 \\
\hline
\end{tabular}

Source: Author's calculation

The first column of Table 1 contains the results for the whole Survey, while the third and the fourth column contain separate results for female and male respondents. The values in the second column are calculated by the Eurostat and presented in their database (http://ec.europa.eu/eurostat /data/database). The presented results show the difference between women and men $-40 \%$ of women do not have any Information skills, in comparison to $23.1 \%$ of men. The difference exists within other categories in favor of men.

Table 2: Communication skills frequency

\begin{tabular}{lrrrr}
\hline \multirow{2}{*}{ Level } & \multicolumn{2}{c}{ All respondents } & \multirow{2}{*}{ Women } & \multirow{2}{*}{ Men } \\
\hline No skills & 32.8 & 38.0 & 40.5 & 25.1 \\
Basic skills & 16.5 & 13.0 & 14.1 & 19.6 \\
Above basic skills & 50.7 & 49.0 & 45.4 & 55.3 \\
\hline
\end{tabular}

Source: Author's calculation

The similar results are for the Communication skills, with a note that the percent of women with Basic skills is higher than in the previous case.

Table 3: Problem solving skills frequency

\begin{tabular}{lrrrr}
\hline \multirow{2}{*}{ Level } & \multicolumn{2}{c}{ All respondents } & \multirow{2}{*}{ Women } & \multirow{2}{*}{ Men } \\
\cline { 2 - 3 } & \multicolumn{1}{c}{ Survey } & \multicolumn{1}{c}{ Eurostat } & & \\
\hline No skills & 38.7 & 44.0 & 44.8 & 41.3 \\
Basic skills & 15.9 & 20.0 & 19.3 & 15.4 \\
Above basic skills & 45.4 & 36.0 & 35.9 & 43.3 \\
\hline
\end{tabular}

Source: Author's calculation 
For the dimension of Problem solving skills, the results show that the difference between women and man is reduced. The number of women with Basic problem solving skills is higher than man, while the number of men with Above basic skills is slightly higher.

Table 4: Software skills frequency

\begin{tabular}{lrrrr}
\hline \multirow{2}{*}{ Level } & \multicolumn{2}{c}{ All respondents } & \multirow{2}{*}{ Women } & \multirow{2}{*}{ Men } \\
\hline No skills & Survey & \multicolumn{1}{c}{ Eurostat } & & \\
Basic skills & 57.5 & 58.0 & 60.9 & 54.2 \\
Above basic skills & 15.7 & 15.0 & 18.5 & 12.8 \\
\hline
\end{tabular}

Source: Author's calculation

The last dimension - Software skills are considered to be most demanding. At the level of the whole sample, it is noticeable the rapid growth in the number of respondents without any skills, almost $60 \%$. The number of women with Basic software skills is also higher, while the results are in favor of man for the Above basic skills level.

Table 5: Digital skills indicator frequency

\begin{tabular}{lrrrr}
\hline \multirow{2}{*}{ Level } & \multicolumn{2}{c}{ All respondents } & \multirow{2}{*}{ Women } & \multirow{2}{*}{ Men } \\
\hline No skills & Survey & \multicolumn{1}{c}{ Eurostat } & & \\
Low skills & 22.2 & 17.3 & 33.1 & 22.3 \\
Basic skills & 26.8 & 25.5 & 29.5 & 24.4 \\
Above basic skills & 24.4 & 26.0 & 14.1 & 23.7 \\
\hline
\end{tabular}

*www.digital-agenda-data.eu

Source: Author's calculation

Finally, Table 5 contains the values for Digital skills indicator. This indicator recognizes four levels (the Low skills is additional level). The presented values confirm previous results - the higher percentage of women in Serbia do not have any digital skills or have low skills.

\section{Conclusion}

In this paper, we report findings of a pilot survey study conducted in Serbia based on standardized questionnaires on a purposive sample, aimed 
to shed light on the existing level of digital skills of working population in Serbia, with focus on the gender gap. We analyzed digital skills grouped into four dimensions comprised of the survey - Information skills, Communication skills, Problem solving skills and Software skills.

Results of the survey show that the overall level of digital skills of the workforce in Serbia, measured by Eurostat's' Digital Skills indicator, have much space for improvement. Almost half of the respondents (49\%) have low digital skills or do not have any skills at all. Nevertheless, values for Serbia do not deviate significantly from EU average (17.3\% in EU do not have digital skills, $25.5 \%$ have low skills, $26 \%$ have basic skills and $31.2 \%$ have above basic skills), but in some EU countries, the situation is much better. For example, in Norway only $2.9 \%$ do not have any digital skills, in Luxembourg, $11.7 \%$ have low skills, in the Czech Republic, $35.8 \%$ have basic skills, and again in Luxembourg, 55.3\% have above basic skills.

We also show the existence of gender gap in digital skills or digital divide among working population in Serbia. The calculation for women shows that $62.6 \%$ of respondents do not have any digital skills or have low skills, while $37.3 \%$ have basic and above basic skills. The calculation for men show that $46.7 \%$ of respondents do not have any or have low skills, while 53.2\% have basic and above basic skills, and these results are in line with EU average.

These results point to the conclusion that policymakers in Serbia should have in mind these differences and adjust the policies to support women education in the field of digital knowledge. Empowering women and increasing their digital literacy would have impact on decrease of the gender gap in Serbia, increase of female entrepreneurs and reduction of poverty.

\section{Acknowledgements}

This paper is a result of research projects under the code 179015 (Challenges and Prospects of Structural Changes in Serbia: Strategic Directions for Economic Development and harmonization with EU requirements) and 47009 (European Integrations and Socio-economic Changes in the Economy of Serbia on the Way to the EU) financed by the Ministry of Education, Science and Technological Development of the Republic of Serbia. 


\section{Limitations of the Study}

As this study is survey-based, a representative sample is required. The appropriate sample has been taken, but a much larger sample size would give better results, and for that reason, we compare our results with Eurostat. The findings of the study are based on the expressed perceptions of the respondents about their digital skills, but not on the objective measure like a test.

\section{References}

[1] Adult Education Society. 2010. "Start of "Second Chance" project in Serbia." Available at http://www.aes.rs/en/pocetak-second-chance-projektau-srbiji/.

[2] Ainley, John, Wolfman Schulz, and Julian Fraillon. 2016. "A global measure of digital and ICT literacy skills". Background paper prepared for the 2016 Global Education Monitoring Report, Education for people and planet: Creating sustainable futures for all. Australian Council for Educational Research

[3] Bimber, Bruce. 2000. "Measuring Gender Gap on the Internet". Social Science Quarterly, 81(3): 868-876.

[4] Carretero, Stephanie, Riina Vuorikari and Yves Punie. 2017. "The Digital Competence Framework for Citizens - With Eight Proficiency Levels and Examples of Use". Joint Research Centre. European Commission. Luxembourg.

[5] Chetty, Krish, Qigui Liu, Li Wenwei, Jaya Josie, Nozibele Gcora and Ben Shenglin. 2017. "Bridging the Digital Divide: Measuring Digital Literacy". G20 Insights - Think 20 Dialogue. Germany.

[6] Covelo, Stephen. 2010. "A Review of Digital Literacy Assessment Instruments". IDE-712: Analysis for Human Performance Technology Decisions, Front-End Analysis Research. Syracuse University, School of Education/IDD \& E.

[7] European Commision. 2016. "Skills Agenda for Europe". Document available at: https://ec.europa.eu/transparency/regdoc/rep/1/2016/EN/12016-381-EN-F1-1.PDF

[8] European Commission. 2015. "Digital Single Market Strategy". Document available at: https://www.eu2017.ee/sites/default/files/2017-09/EC\%20for\% 20TDS_The\%20Digital\%20Single\%20Market\%20Strategy.pdf.

[9] European Commission. 2018a. "Digital Education Action Plan". Document available at: https://ec.europa.eu/education/sites/education/files/ factsheet-digital-education-action-plan.pdf. 
[10] European Commission. 2018b. "Women in the Digital Age". Document available at: http://ec.europa.eu/newsroom/dae/document.cfm?doc_id=50224.

[11] European Parliament - Policy Department for Citizen's Rights and Constitutional Affairs. 2018. "The Underlying Causes of the Digital Gender Gap and Possible Solutions for Enhanced Digital Inclusion of Women and Girls", Brussels.

[12] Gui, Marco, Argentin, Gianluca. 2011. "Digital Skills of Internet Natives: Different Forms of Digital Literacy in a Random Sample of Northern Italian High School Students." New Media \& Society, 13(6): 963-980.

[13] Gunkel, David. 2003. "Second thoughts: Toward a critique of the digital divide". New Media \& Society, 5, 499-522.

[14] Hafkin, Nency, Sophia, Huyer. 2007. "Women and Gender in ICT Statistics and Indicators for Development". The MIT Press. 4(2): 25-41.

[15] Hilbert, Martin. 2011. "Digital gender divide or technologically empowered women in developing countries? A typical case of lies, damned lies, and statistics." Women's Studies International Forum. 34(6): 479-489.

[16] Jones, Steve, Johnson-Yale, Camille, Millermaier, Sarah, and SeoanePérez, Francisco. 2009. “U.S. College Students' Internet Use: Race, Gender and Digital Divides." Journal of Computer-Mediated Communication, 2(1): 244-264.

[17] Khateeb, Ahmed, Abdulteeef. 2017. "Measuring Digital Competence and ICT Literacy: An Exploratory Study of In-Service English Language Teachers in the Context of Saudi Arabia". International Education Study, 10(12): 38-51.

[18] Kolaković, Kristijan, Vladimir, Marinković, Saša, Stefanović. 2009. "Employee Development and Knowledge-Based Organization." Economic Analysis, 42(3-4): 69-77.

[19] Lakić, Dragana, Parojčić, Jelena, Kovačević, Nada, and Antonijević, Milan. 2012. "Digital literacy of employers and students in Serbia. Conference: Employer Engagement in a Digital Age." Universtiy of Greenwich.

[20] Martin, Allan, and Jan Grudziecki. 2006. "DigEuLit: Concepts and Tools for Digital Literacy Development", University of Glasgow, Scotland. Available at: https://www.tandfonline.com/doi/full/10.11120/ital.2006.05040249?scro $11=$ top\&needAccess $=$ true.

[21] Ministry of Education, Science and Technological Development of the Republic Serbia. 2017. "Digital Competences Framework - Teacher for a Digital Age”.

[22] Official Gazette RS, no. 107/2012. 2012. "The Strategy for Education Development in Serbia until 2020." 
[23] Radović-Marković, Mirjana, Marković, Dušan, Simović, Vladimir, Medić, Zorica, and Živadinović, Jovan. 2017. „E-Learning as a Tool for Empowering Entrepreneurship.“ Journal of Women's Entrepreneurship and Education, (3-4): 65-72.

[24] Radović-Marković, Mirjana. 2011. „New Schools for Entrepreneurs and Managers: Education for Female Entrepreneurship.“ Journal of Women's Entrepreneurship and Education (1-2) : 77-88.

[25] United Nations ECLAC. 2013. "Women in the Digital Economy: Breaking through the equality threshold". XII Regional Conference on Women in Latin America and the Caribbean. Santiago. Chile.

[26] Zhao, Houlin. 2016. "Encouraging more women and girls in ICT, How can we close gender gap”. ITU News Magazine. Geneva, Switzerland.

Article history: $\quad$ Received: 15 April, 2018

Accepted: 16 June, 2018 